\title{
Procesos de construcción de identidad entre la población inmigrante
}

\section{Sonia Veredas Muñoz}

Universidad Complutense de Madrid. Facultad de Educación.

Departamento de Sociología de la Educación

Paseo Juan XXIII, s/n. 28040 Madrid. Spain

sveredas@ccedu.ucm.es

\section{Resumen}

En el presente artículo se reflexiona sobre los procesos de reconstrucción de la identidad entre los inmigrantes marroquíes y peruanos en España. El «salto» migratorio condiciona la redefinición en las formas de autopresentación individual a partir del contacto con el entorno receptor. Categorías como clase social, género, etnia, religión, nación o filiación política operan decisivamente en este proceso, que debe entenderse también en relación con los nuevos condicionantes ambientales. Damos cuenta, pues, de un proceso dinámico de construcción social que tiene su correlato en la realidad subjetiva del inmigrante.

Palabras clave: inmigración, identidad, marroquíes, peruanos.

\section{Abstract}

In this article we examine the different ways moroccan and peruvian immigrants reconstruct their personal identity in Spain. The migration affects the individual self-presentation mechanisms because of the presence in a new society. Variables as social class, ethnicity, religion, nation or political affiliation are relevant in this phenomenon, which must be also interpreted in the context of new social conditions. We describe, in cconsecuence, a dynamic process of social construction correlated with individual subjectivity.

Key words: immigration, identity, Marrocans, Perucians.

\section{Sumario}

1. Formas de reconstrucción de la identidad entre inmigrantes y refugiados peruanos
2. Formas de reconstrucción de la identidad entre los inmigrantes marroquíes

Bibliografía 
Mi reflexión acerca de las formas de reconstrucción de la identidad entre la población inmigrante peruana y marroquí en Madrid se inscribe dentro de un trabajo más amplio sobre el estado del asociacionismo inmigrante entre ambas poblaciones y realizado en base a técnicas de análisis fundamentalmente cualitativas, sobre todo estrevistas personales y observación participante y no participante. Dado que una de las interpretaciones posibles del fenómenos asociativo tiene que ver con la consideración de estas estructuras organizativas en tanto que manifestaciones, también lugares de construcción y reconstrucción, de la identidad colectiva, mi interés es intentar dilucidar hasta qué punto tales manifestaciones arraigan entre las poblaciones consideradas. Dejo de lado en este escrito el examen de las vías de construcción colectiva de la identidad inmigrante para centrarme en la reflexión acerca de los procesos individuales de construcciónreconstrucción de la misma en el contexto migratorio.

Por lo demás, la definición del concepto identidad resulta inseparable de la de alteridad, como afirma J.L. Aranguren (1993): «el otro está en el origen de mi yo", de modo que el examen del contenido de aquél nos remite inexcusablemente a la relación entre el individuo y su entorno y obliga a entenderlo desde una visión dialéctica, para E. Landowski (1993) la noción de "sí» solo se descubre en el «entre sí». Lo cierto, sin embargo, es que la aprehensión "desde fuera» de la identidad individual resulta tan problemática que apenas puede abordarse de una aproximación meramente sintomática. La segunda dificultad en este caso deriva de la estructura multidimensional de las identidades (donde el referente puede ser la nación, la religión, la lengua, la raza...) y del hecho de que el «difícil equilibrio de esas identificaciones alternativas y/o complementarias debe ser construido cotidianamente en función de los contextos de acción, de las circunstancias, de las situaciones, de los talantes, de los interlocutores» (E. Lamo de Espinosa, 1995: 26). Ciertamente, la situación migratoria define un contexto de privilegio en la reflexión acerca del fenómeno que nos ocupa, dado que los referentes individuales y sociales para el inmigrante se modifican y, por tanto, su autopercepción y formas de autopresentación en el nuevo entorno.

Este —el de la identidad - es quizás el aspecto más escurridizo de cuantos se abordan en el estudio de la inmigración. La afirmación de la propia identidad no suele ser explícita y el estudioso ha de estar atento a señales que aprenderá a captar a medida que vaya ampliando su conocimiento sobre el grupo. Raramente la identidad se expresa en términos afirmativos sino sobre todo desde la negación, el establecimiento de distancias respecto a otros grupos, por eso el estudio de las relaciones interpersonales resulta relevante en este sentido. Sí conviene recordar, tal como afirma G. Simmel, que la situación social del inmigrante y su propia identidad vienen marcadas por su condición de sujeto fronterizo entre dos mundos, dos sociedades: «el intruso que con sus diferentes funciones sociales habita en esa tensión del afuera y enfrente pero dentro» (G. Simmel, 1977). Y es que el término escurridizo no se refiere sólo a las dificultades inherentes a cualquier disgresión sobre esta cuestión, sino también al hecho de que la condición de inmigrante sitúa al individuo en una 
situación ciertamente inestable en cuanto a la propia consideración, identidad, se refiere: «Ni ciudadano ni extranjero ni totalmente al lado de uno mismo ni totalmente al lado del otro, el inmigrante se sitúa en ese lugar bâtard del que habla también Platón, la frontera del ser y el no-ser social»1. En términos de A. Tornos (1994), la crisis de identidad deriva de la separación entre lo que somos y lo que hacemos, entre los valores personales y la posibilidad de ponerlos en práctica en la sociedad en que se ubica el individuo: en el contexto migratorio, y sobre todo entre algunos grupos inmigrantes, «es máxima [...] la falta de correspondencia entre los valores por los cuales habían aprendido a dignificarse y la vida cotidiana que devora todas sus energías».

El examen de las diferentes formas de aproximación al tema de la construcción de la identidad permite afirmar ciertos extremos al respecto. En primer lugar, hay dos vías de abordar el tema: una perspectiva individualista y otra de carácter sistémico o social. No creo que sean excluyentes y, en vista de mis observaciones, defiende la necesidad de incorporar ambas visiones de cara a un acercamiento más completo al tema: la identidad no es sólo un proceso dinámico de construcción social, sino también una realidad subjetiva (I. Burkitt, 1991). Hablar de reconstrucción o de readaptación de la identidad implica en sí la opción por la perspectiva construccionista (frente a la esencialista) en el estudio de las relaciones interétnicas. Esto supone definir la etnicidad como construcción social y abordar el estudio de las relaciones étnicas desde una perspectiva social, no cultural: enfatizar, por tanto, los aspectos sociales y estructurales relacionados con la construcción de lo que se ha denominado nueva identidad. Categorías como clase social, género, etnia, religión, nación o filiación política operan decisivamente en este proceso, además de los aspectos relativos a la representación del «otro», es decir, a la transmisión de estereotipos relativos a aquél ${ }^{2}$. Por supuesto, la reconstrucción tiene lugar siempre a partir de ciertos materiales que asumimos como parte del bagaje cultural del grupo, pero tampoco éste es definible en términos esencialistas. Es decir, frente a las explicaciones sistémicas de la cultura elaboradas desde el estructuralismo - cultura como conjunto cerrado e integrado-, optamos por subrayar el papel de aquélla en la adaptación colectiva al medio y el margen de autonomía individual en la comprensión e interpretación de la realidad, perspectiva que implica el cuestionamiento de la identidad individual como correlato inmediato de la cultura, más bien la entiende como acontecimiento: la adhesión e identificación no es un a priori, se produce. De este modo, las distintas opciones identitarias de que daré cuenta pueden conceptualizarse como res-

1. Bourdieu, P. (1991). Prefacio a L'immigration. Sayad, Abdelmaleck (ed.). De Boeck Université.

2. Es decir, identidad como «metáfora de la subjetividad humana que constituye la "expresión semiótica del contacto entre el organismo y el ambiente externo" y debe ser objeto de una comprensiva interpretación socioideológica, en el sentido de signo, significado». Traverso Yépez, M. (1995). "Categorías en la construcción de la identidad nacional latinoamericana» (poligrafiado), entrecomillados de Voloshinov (1992: 52). 
puestas de índole psicológico a condicionantes ambientales. Esta forma de abordar la cuestión no es, ya lo hemos dicho, la única posible, pero tal vez sí la única pertinente en este caso, puesto que, a mi juicio, se adecúa a la realidad de lo que he observado entre las poblaciones inmigrantes peruana y marroquí. No desdeño la dimensión colectiva del proceso de reconstrucción de la identidad inmigrante, simplemente creo que el "salto" es cuestión de tiempo y que las condiciones para que se verifique la construcción colectiva de la identidad aún no están dadas. En este sentido, recuperando aquí la aportación de E. Goffman (1987), acaso sería más correcto definir la mayoría de las opciones adaptativas descritas a continuación como formas de autopresentación que se modifican a raíz del cambio de auditorio que supone la migración, donde la sociedad española acaso pueda conceptualizarse como la región anterior de la representación, mientras el resto de los compatriotas emigrados constituyen la región posterior, donde aquella se relaja: "Así, cuando el individuo se presenta ante otros, su actuación tenderá a incorporar y ejemplificar los valores acreditados [...], a encubrir, a dar menos importancia a aquellas actividades, hechos o motivos incompatibles con una visión idealizada de sí mismo y de sus obras» (E. Goffman, 1987: 47 y 59). En una situación de migración relativamente reciente, considero que lo más correcto es tratar dichas opciones como presentaciones dramatúrgicas del yo en situaciones de interacción (fenómeno circunstancial) que como modificaciones en la identidad profunda (entendida como sitema valorativo personal desde el cual uno se representa a sí mismo e interpreta el entorno y sus relaciones con él).

Hay que advertir, además, que el proceso de reconstrucción de la identidad no es inmediato sino gradual y que por eso apenas se atisba entre quienes acaban de abandonar su país de origen ${ }^{3}$. En la diáspora cada uno se reinventa en cierta forma y tal depende, según creo, de las condiciones de partida y de llegada, del desajuste entre ellas y las formas valorativas del nuevo contexto. $\mathrm{El}$ «renacer» que posibilita en cierta medida la emigración se orienta de acuerdo con diversos factores y de diferente índole: cada uno se reconstruye en cierta forma de acuerdo con lo que concibe como deseable — sistema de valoresy también de acuerdo con lo que le permite la nueva posición social en que se ubica. Partiendo de estos elementos, el individuo selecciona el referente identitario que mayor seguridad personal le reporta y del que sale mejor parado relativamente: clase social, etnia, lugar de origen..., el que más le rinde. En concreto, los factores que, a mi juicio, operan en la reconstrucción de la identidad inmigrante - peruano o marroquí — son fundamentalmente los siguientes: carácter (español/inmigrante) del entorno personal inmediato; estatus social de partida (nivel de estudios y ocupación en el país de origen); condición jurí-

3. El significado del proceso de reconstrucción identitaria ha sido bien expresado en otro lugar por E. RAMírez GOICOECHEA (1996: 294): «las operaciones y manipulaciones de autoadscripción étnica y clasificatoria permiten al sujeto reubicar su alteridad social, invertir su significado, negarla, proyectarla, adscribirse segmentariamente a grupos de referencia simbólica más abstractos "los blancos", "los europeos", "los latinos", etc.) asociados por contigüidad a la normalidad social, así objetivada». 
dica del inmigrante (refugiado o inmigrante económico ${ }^{4}$ ); tipo de movilidad (ascendente o descendente) operada tras la migración y tipo de emigración (individual o familiar). El elemento que vehicula en buena medida el efecto de los factores mencionados en el nivel individual de la autopercepción es el entramado de relaciones sociales privilegiadas en el contexto receptor, no cabe obviar la dimensión colectiva de los procesos de construcción de la identidad. La selección del entramado de relaciones sociales en que se mueve el emigrante en el país de destino implica una dimensión volitiva tremendamente clarificadora de los cambios en la autopercepción. Además, como ocurre en la selección del entorno inmediato de relaciones personales, parece existir implícita dentro de la opción identitaria del individuo una dimensión instrumental nada desdeñable, por cuanto la asunción de nuevos patrones valorativos y de comportamiento puede estar motivada por las previsiones acerca del rendimiento social de los mismos en el nuevo contexto. En este punto hay que tener en cuenta dos aspectos: en primer lugar, el nuevo contexto puede no ser tan nuevo si el entorno inmediato del inmigrante es peruano y sus coordenadas de referencia, por tanto, lo son. En segundo lugar, la retribución no incluye sólo aspectos materiales sino también psicológicos. Hay, pues, opciones en las que se maximiza la importancia de la autopercepción y por tanto los aspectos psicológicos de la retribución, y otras en las que parecen pesar en mayor medida los materiales. De todos modos, estas opciones funcionan mejor como tipos ideales en el sentido weberiano que como modelos reales: ni las primeras descuidan los aspectos materiales del rendimiento ni las segundas se desarrollan al margen de factores de índole psicológico. Lo que resulta indudable es el componente bidireccional del proceso de reconstrucción de la identidad, por cuanto nunca se verifica independientemente del «otro»: la cuestión es qué «otro» se tome como referencia y es ahí donde entran en juego los aspectos relativos a la retribución y, por ende, al efecto de la forma en que el inmigrante se sienta percibido y tratado en la sociedad española. Queda claro, además, que no es un proceso reducible a coordenadas psicológicas, por cuanto incorpora un evidente contenido cultural e ideológico: la medida en que uno elabora su «carta de presentación» responde a lo que cree socialmente adecuado en el entorno de referencia (inmigrante o autóctono).

\section{Formas de reconstrucción de la identidad entre inmigrantes y refugiados peruanos}

Antes de hablar de redefinición de la identidad habría que preguntarse si existe «una» identidad peruana. La composición multiétnica del país andino y su

4. La adopción de la condición jurídica del inmigrante como posible condicionante de su opción identitaria no es más que una grotesca medida adoptada en vista de las diferentes implicaciones psicológicas que derivan del hecho de marcharse (inmigrante económico) o ser expulsado (aislado político) de un país. La autopercepción, ya lo hemos dicho, condiciona la opción identitaria del inmigrante. 
evidente fragmentación espacial y económica — simplificada en la trilogía selva/sierra/costa - no permiten realmente hablar de tal identidad como un hecho único. ¿¿Donde radica tal identidad?: ‘acaso en una minoría blanca fragmentada en dos bandos, el hispanófilo y el sajón, proyectado el primero en su origen español y el segundo en el referente calvinista estadounidense?; ¡es el indio puro el depositario de lo que pueda denominarse «identidad peruana»? Tal vez, como afirma el historiador José Ramón García 5 , el verdadero Perú es la mezcla de lo blanco y lo indio, es la población mestiza... el Perú de «todas las sangres», como diría Arguedas. Tanto la población blanca —cuyos referentes se encuentran fuera del país - como la netamente india — aislada en la selva y organizada económica y socialmente bajo parámetros propios- carecen de identidad peruana, entendida como conciencia de pertenencia e integración en un modelo nacional con proyección de futuro. El origen mestizo de gran parte de los inmigrantes peruanos en España — aunque no de todosnos ayuda a salvar en buena medida este escollo, pero es preciso no perder de vista estas consideraciones en la explicación de las formas de autopresentación detectadas.

\subsection{Exageración de la posición social originaria en Perú}

Éste no es un fenómeno que se verifique exclusivamente entre la población inmigrante peruana. Tanto marroquíes como peruanos tergiversan en sus formas de autopresentación ciertos datos relativos a la zona geográfica de procedencia y a la clase social de origen. Es cuestión de deseabilidad social, de compensar la pérdida generalizada de estatus social a consecuencia de la inmigración reinventando un pasado que no fue tal pero que, en todo caso, el interlocutor español no tiene forma de verificar ${ }^{6}$.

\subsection{Estrategia de «camuflaje»: españolización del fisico o del acento}

Los aspectos instrumentales de esta estrategia incluyen la evasión del control policial y la eliminación de la desigualdad en cuanto al acceso al trabajo; también el facilitamiento de los contactos con los españoles. El «camuflaje» (teñido de pelo, vestimenta...) pretende eliminar los signos externos que identifican a la persona como peruana. Es una suerte de asimilación externa que implica la

5. Revista Quipu, 6. Madrid, abril de 1997.

6. En este sentido, recuperando de nuevo la reflexión goffmaniana, hay que tener en cuenta que el inmigrante se mueve en un mundo bifronte, donde la segregación de auditorios - español y peruano, en términos generales - posibilita la construcción de una fachada, incuestionable en uno de ellos pero no en el otro. La tergiversación de la clase social de origen o de la zona geográfica de procedencia puede no ser detectada por el auditorio espanol, pero difícilmente será creíble la reinvención ante un compatriota: «[...] así como es provechoso para el actuante excluir del auditorio a las personas que lo perciben en otra representación incompatible, también ha de ser ventajoso para él excluir del auditorio a aquéllos ante quienes representó en el pasado una actuación incompatible con la presente» (E. Goffman, 1977: 149). 
asunción de pautas conductuales o valorativas de la sociedad receptora y que he detectado en mayor medida entre personas que muestran y expresan un sentimiento positivo, una vinculación emocional, hacia España y los españoles.

\subsection{Estrategia de "acriollamiento»}

El fenómeno de ocultamiento del origen serrano o «acriollamiento» se evidencia en una práctica bastante común entre los peruanos inmigrantes que proceden de departamentos de la sierra pero afirman en España que son de Lima (a menudo emigraron antes allí para trabajar). Aquí ningún español conoce al inmigrante, ¿quien dudará que procede de la capital peruana? El serrano, el cholo, no está precisamente bien considerado entre los costeños, que lo contemplan con desprecio desde su piel más blanca y su avidez de todo lo europeo o estadounidense ${ }^{7}$. El racismo está presente en la cotidianidad de un pueblo donde coexisten multitud de razas y que incorpora definitivamente la diferencia a este nivel en su sistema de estratificación social.

\subsection{Recuperación del orgullo indígena}

La recuperación del orgullo indígena tiene lugar a menudo entre quienes en absoluto alardearon de sus raíces indias en el país de origen ${ }^{8}$. Esto tiene que ver con el proceso de movilidad social descendente que sufre la mayoría de estos inmigrantes al venir a España y con la consiguiente pérdida de prestigio social y sacudida de la autoconciencia. Esta forma de autopresentación tiene evidentes efectos compensatorios y es, desde luego, una reelaboración culta que acontece una vez superado el mito de la superioridad étnico-racial criolla. Si esto se da en mayor medida entre refugiados se debe no sólo a su considerable nivel de estudios — según T. Altamirano (1992) el «redescubrimiento" ocurre entre los migrantes de clase media y alta- y al hecho de que forma parte de su discurso político-ideológico (autoidentificación con el grupo oprimido), sino también, según creo, a que su frecuente situación de aislamiento personal no posibilita la readaptación identitaria en el grupo de vínculos primarios.

7. Es posible relacionar este fenómeno de "acriollamiento" con lo que M. Roitman (1992) ha descrito en otro lugar: la interiorización por parte de las clases sociales subalternas, mayoritariamente mestizas, del odio y el resentimiento contra lo indígena, como parte del proyecto de dominación criolla que en Latinoamérica ha venido justificándose en el mito de la superioridad étnico-racial.

8. «Es frecuente escuchar decir a los migrantes que se sienten más peruanos estando fuera del Perú, que redescubren el Perú estando lejos de él. Los migrantes de clase media y alta, que en general no se identificaban con la música de la Sierra y con la cultura andina, una vez que están fuera del Perú redescubren el Ande y sus tradiciones culturales. Las mujeres hacen desfile de modas usando vestimenta campesina o indígena con acompañamiento de melodías como El Cóndor pasa, Valicha o un Huaylarsh huancaino» (T. Altamirano, 1992). 
Intentaré explicar por qué defino este proceso como reelaboración culta. Hablar de eleboración significa eliminar la posibilidad de entenderlo como fenómeno espontáneo y no lo es, porque lo más frecuente es que el individuo opere la recuperación después de haber intentado esconder sus raíces indias o haberlas obviado durante toda su vida. Lo que instintivamente se oculta, en razón del estigma social que lo marca, solo intelectualmente puede recuperarse. Y esta recuperación solo es posible desde la dignificación de lo indígena que tiene lugar a raíz del conocimiento racional de su razón histórica y no es ajena a la orientación de la «antropología indigenista» (R. Aparicio y A. Tornos, 1997) que en el país andino ha marcado la enseñanza elemental y los medios de comunicación. Sin embargo, la recuperación del orgullo indígena no opera siempre de igual manera. En realidad, cabría distinguir en este apartado entre dos opciones identitarias no estrictamente asimilables. En primer lugar, podríamos hablar de recuperación orgullosa del pasado imperial: en algunos casos, sobre todo entre los refugiados, se hace referencia a la gloriosa edad precolonial, el individuo se remite a algo, el incanato, en buena medida idealizado y que se evoca como civilización excepcionalmente avanzada y cruelmente destruida por los españoles.

En cuanto a la segunda opción, sí podríamos hablar en sentido estricto de recuperación del orgullo indígena: se habla de las propias raíces, de la situación de rechazo y menosprecio vivida personalmente y de la superación personal de ese miedo, recuperando paulatinamente modos y formas — música, giros lingüísticos...- hasta entonces silenciados. Si en ambos casos se trata de un proceso de recuperación intelectual, elaboración culta (elevado nivel de estudios), en el primero el contenido ideológico del mismo es más evidente, mientras en el segundo la humillación y el desprecio se han sufrido en el propio Perú, al emigrar a Lima, de modo que la recuperación tiene más de proceso emotivo personal y vivido. Esta forma de expresión cultural está muy cerca de lo que se ha definido como «absolutismo étnico», en cuanto regreso a la cultura original, reconstrucción operada desde una posición de subordinación también interiorizada a nivel personal y que se ha superado, y en ese sentido es definible como "etnicidad reactiva» (Hechter, 1975), es decir, como construcción de la etnicidad desde una situación de estigmatización social de lo indígena.

Los factores que orientan de forma primordial la identidad y autopresentación del asilado se refieren sobre todo a su antigua condición de luchador social, de militante político, de líder. En ese sentido, su referente supera las barreras nacionales y étnicas, en un hermanamiento con quienes, como él, han dedicado parte importante de sus vidas a intentar modificar situaciones sociales injustas y han debido abandonar su país por llegar a peligrar sus vidas. La autoconciencia en el exilio está muy relacionada con la forma en que uno se perciba en relación con la situación en que estaba en el país de origen. La diferencia fundamental entre refugiados e inmigrantes económicos radica en que los primeros suelen ser personas que tenían una vida hecha y muy hecha en el país de origen. No es gente a la que acuciara la falta de expectativas o posi- 
bilidades, están aquí porque les sobraban: la prueba es que han podido escapar del Perú. Para el verdadero refugiado, la salida no es una elección, es la única posibilidad. A nivel psicológico esto tiene repercusiones claras cuando se opera el salto al nuevo contexto, un lugar donde es preciso partir de cero en condiciones adversas y donde las posibilidades de desarrollar la actividad profesional para la que se está preparado son ciertamente escasas. Hay que partir de cero también porque aquí se es un «don nadie», porque el reconocimiento que en Perú se obtenía en determinados círculos a raíz del activismo político o social ha desaparecido, porque en España se es solo un inmigrante más. Doblemente, pues, traumática la pérdida: atrás no queda solo la tierra donde se nació, la gente entre la que cada uno creció, atrás queda también parte de uno mismo, la parte que en cierta medida compensaba psicológicamente el riesgo de perder la libertad o la vida, ese reducto del «yo» inmune a las armas y las amenazas. Aquí ya no hay peligro de muerte, están a salvo, pero el coste es considerable: la identidad personal se tambalea. Aquí no existe el luchador, el líder, el compañero solidario. El dolor se agrava ante la imposibilidad de dar más sentido a la partida que el de huida: el exilio no es un paréntesis vital, es un punto y aparte. El peruano que sale de su país para hacer algún dinero en Europa, mantiene su proyección vital en el país de origen: aunque en muchos casos acabará estableciéndose definitivamente aquí, la asunción del cambio de planes es muy costosa psicológicamente y, por tanto, gradual. El refugiado, sin embargo, tiene que beber de un trago lo que los demás beben a sorbos, muy lentamente. Ciertamente, siembre se espera "que caiga el chino», que se anulen las penas de cárcel pendientes o las órdenes de búsqueda y captura, pero nadie se engaña: que la situación política en Perú cambie no es algo que ahora esté en manos de quienes huyeron. En estas circunstancias, la recuperación del orgullo imperial —como táctica «ofensiva» de autopresentación frente a lo reactivo del camuflaje, que no hace de la diferencia un valor sino que pretende eliminarla - no sorprende en personalidades fuertes y luchadoras, que afrontan una doble humillación, la de la expulsión y la de la degradación social en España.

Vemos, en definitiva, que las estrategias de «camuflaje» y «acriollamiento» o la denominada en términos generales "recuperación del orgullo indígena», son construcciones ideológicas de compensación psicológica. Las reacciones son distintas porque los puntos de partida y grupos de referencia también lo son. Dos caras de una misma moneda, pues, que a mi juicio evidencian la limitación de las alusiones simplificadoras al «resurgir del indigenismo» y la necesidad de hacer referencia a determinados mecanismos de corte ideológico tendentes a operar en el individuo cierta compensación personal por el desprestigio social que a menudo conlleva la condición de inmigrante.

\subsection{Estrategia de "desmarcamiento" de los compatriotas}

Cuando tras la migración tiene lugar una excepcional —en relación con los demás peruanos inmigrantes- mejora en la situación económica personal, 
algunas personas buscan desmarcarse de sus compatriotas al tener una experiencia subjetiva de promoción social y en vista de la desfavorable posición del inmigrante extracomunitario en la jerarquía social y el imaginario colectivo español. Esta estrategia en cierta forma es asimilable al «síndrome del nuevo rico» y por tanto no obedece a factores de orden étnico o cultural. Cuando el inmigrante ha conseguido en España una posición social acorde a su preparación, el cambio en el sistema de referencias volitivas en cuanto a la autopercepción supone el énfasis en la clase social y condiciona la selección de la red de relaciones personales y las formas de presentación social. En los casos de movilidad descendente el referente autoclasificatorio se mantiene en Perú, desde esa perspectiva la pérdida es menor y es mitigable desde las «invenciones» sobre el origen étnico y la clase social de partida.

La pregunta que surge al hilo de esta reflexión sería: ¿̨puede la promoción económica en la sociedad receptora — no hablo de mayores ingresos en términos absolutos sino de mejora de la posición económica en términos relativos y en relación con la sociedad de origen- mitigar la necesidad de estos procedimientos ideológicos de compensación psicológica, en vista de la recompensa recibida a través de la mejora material? No puedo responder sin dudar a esta pregunta. Lo que sí creo es que, en general, el recurso a mecanismos psicológicos de compensación se mitiga si la proyección individual se mantiene en coordenadas peruanas. Desde esta perspectiva, la consideración social de inmigrante es mucha: el hijo es el orgullo de los padres y la admiración del vecindario; el inmigrante es el artífice de la promoción económica de los suyos en Perú, ante todos es un triunfador. La estrategia de «camuflaje» o de recuperación del orgullo indígena no son mecanismos, obviamente, que se orienten a la sociedad de partida.

\section{Formas de reconstrucción de la identidad entre los inmigrantes marroquíes}

\subsection{Identificación africana}

Puede resultar sorprendente este fenómeno entre los inmigrantes marroquíes. Pero lo cierto es que muchos se definen como africanos, como negros, porque en España a todos los efectos (disposiciones legales, relaciones con los españoles $)^{9}$ lo son. Si nada en su país de origen llevaba al marroquí a afirmar su negritud, todo aquí le hace sospechar que es tan negro como un senegalés, y quienes anteponen en el nuevo contexto su sentimiento de clase a las diferen-

9. Es evidente que el estudio sociológico de la inmigración se verifica desde la construcción de conceptos con evidente contenido ideológico, pero con una fuerte repercusión sobre la realidad social: las palabras conjuran y el término inmigrante ha terminado por aplicarse exclusivamente a los procedentes de terceros países, sobre todo a los del sur; sobre este particular, es obvio que también las disposiciones legales en relación con el tema tienen parte de responsabilidad. 
cias nacionales o raciales, así se perciben. Es más frecuente que esta reacción se verifique en mayor medida entre los inmigrantes más antiguos y los de mayor nivel de estudios, precisamente porque exige un tiempo despojarse de los criterios importados al emigrar y modificar la autoconcepción de acuerdo con la nueva situación y también porque el discurso acerca de las clases sociales opera desde un nivel de elaboración superior.

Por la «identificación africana» es predicable también en un segundo sentido, no solo como expresión de la aprehensión de la comunidad de experiencias respecto a los inmigrantes subsaharianos, sino como recuperación orgullosa e ideológica de la propia condición africana. Se trata de un proceso de reacción frente al trato recibido de la población española y no deja de ser, como entre los peruanos que reivindican su condición indígena, resultado de cierta elaboración culta ${ }^{10}$.

E. Ramírez Goicoechea (1996) afirma la "desidentificación africana» de los inmigrantes magrebíes: el marroquí se siente blanco, mediterráneo, magrebí, no africano. Desde el mirador del estrecho, Marruecos contempla Europa de espaldas al resto de África. Los lazos históricos y culturales de los marroquíes con el África subsahariana son más débiles. Mis observaciones y los testimonios recogidos me llevan a relativizar tales afirmaciones, aunque ciertamente la mayoría de los marroquíes continúan desmarcándose de los subsaharianos y, en un radio más cercano, también de los argelinos, tachados de ladrones y fundamentalistas. En este punto se observa también el efecto del cambio de entorno en la selección de los referentes identitarios del inmigrante, donde la propia construcción incorpora la percepción del «otro», que ahora es el español — «los moros son ladrones», «musulmán = integrista»—, y se elabora a modo de respuesta: «yo no soy ni ladrón ni fundamentalista, es el argelino». Efecto de deseabilidad social, maniobra de salvaguardia de la propia consideración: la identidad, ya lo hemos dicho, es un proceso y no un hecho.

\subsection{Ostentación consumista}

Este fenómeno, relativo sobre todo a la indumentaria personal, puede ser interpretable como otro de los que acarrea la tensión cambio-permanencia en que se desgarra el inmigrante marroquí y su propia sociedad de origen. En este caso cobra también forma a menudo de conflicto generacional, pues la «ostentación consumista» se observa sobre todo entre los jóvenes marroquíes de origen urbano, que demuestran mucha querencia por la estética «moderna» (gorras estilo americano, vaqueros de marca, camisetas grabadas con logotipos comerciales e incluso teñidos de pelo). Esto, como ocurre con la «excesiva» occidentalización de la vestimenta femenina, es mal visto por muchos compatriotas, que ven en tales procederes cierto desmarcamiento del grupo de referencia..., como si el individuo renegara de lo suyo. La dimensión compensatoria de esta estra-

10. Como señala T. San Román (1986), la ideología etnocéntrica posibilita la autoestima en una posición marginal. 
tegia frente a la pérdida de estatus y la estigmatización social que sufre el marroquí en nuestra sociedad es obvia ${ }^{11}$.

\subsection{Sublimación de la identidad de partida}

Ésta es otra de las posibles respuestas individuales al fenómeno de descenso y rechazo sociales experimentados por buena parte de los inmigrantes marroquíes en España. Es posible que se verifique en mayor medida entre la población de más edad pero no en exclusiva en ella. Para expresarlo en términos gráficos e inteligibles, el inmigrante marroquí se hace «más papista que el Papa» y retoma los comportamientos propios del «buen musulmán» con un afán y un escrúpulo que acaso llamarán la atención también en su país de origen. El marroquí en este caso lucha contra el desarraigo aferrándose a lo «suyo»: incapaz de navegar entre corrientes que en ocasiones siente tan opuestas, elige una opción y se mantiene firme en ella aunque esto implique una más clara afirmación de distancias en relación con el español. A veces este fenómeno se verifica después de que el individuo haya intentado la asunción de pautas valorativas y conductuales propias de la sociedad receptora, pero, a la postre, ha vuelto a lo que reconoce y menor coste psíquico le reporta.

\subsection{Sobre la posibilidad de afirmación de la «identidad rifeña»}

Además de la tensión tradición-modernidad que vehicula en buena medida las relaciones intergeneracionales y entre inmigrantes de procedencia ruralurbana, otro de los aspectos más relevantes desde el punto de vista de la identidad y que también condiciona el lugar de las relaciones interpersonales se refiere al origen beréber de buena parte de los inmigrantes marroquíes en España. En cuanto a la posibilidad de la reafirmación de la identidad rifeña en España, recuperamos aquí las afirmaciones de S. Chaker (1991): el grado de fusión histórica, cultural, económica y política de las poblaciones beréberes es tal que no permite una evolución de tipo nacionalista. Hay especificidades culturales innegables, particularismos regionales, pero no conciencia nacional o histórica beréber; falta una conciencia histórica autónoma a largo plazo, vida cultural suficientemente consistente y reconocida capaz de contrarrestar la integración arabo-islámica.

Por mi parte, con la limitación que impone ver las cosas desde fuera pero también con la posición de privilegio que supone ser observador neutral, haré algunas observaciones a partir de lo que mi trato con inmigrantes marroquíes

11. Quiero realizar aquí una aclaración que debe guiar la interpretación del término estigma. Cuando hablamos de estigma, hablamos — según Goffman- de atributos «incongruentes con nuestro estereotipo acerca de cómo debe ser determinada especie de individuos» (E. Goffman, 1970: 13). En consecuencia, inmigrante no es un estigma: el marroquí, obviamente, no es estigmatizado en razón de su condición inmigrante, sino de rasgos culturales o comportamentales reales o virtuales (prejuicios) que no se adecúan a las expectativas y valores de la sociedad receptora. 
me ha permitido notar. En primer lugar, en el imaginario de la población marroquí de origen árabe, el rifeño vendría a ser como el paleto, el ignorante, testarudo y poco abierto a nuevas influencias. Esto no ocurre, sin embargo, entre los árabes con un nivel superior de formación y que han incorporado el registro de clase como parte de la propia identidad. Entre los marroquíes rifeños existe cierto rechazo a Rabat y a Hassan II por lo que representan, un poder político opresor que mantiene la zona del Rif en el olvido, pero cuando por su origen responden mayoritariamente «de Marruecos» o «marroquí» (o de Alhucemas): no les he oído definirse nunca abiertamente como rifeños, aunque algunos presumen de pertenecer a una de las mejores familias de su pueblo. Es decir, entre los emigrantes de origen rifeño las formas de autopresentación no suelen incorporar la dimensión étnica. Ésta es solo recuperada por algunos individuos con mayor nivel de estudios y ha de entenderse de nuevo en tanto elaboración culta, como también lo es la afirmación de la unicidad del grupo en virtud de su común condición social en el país receptor. Hay que tener en cuenta, sin embargo, que la adscripción marroquí entre los rifeños puede significar sobre todo la afirmación de un referente político desde el que presentarse ante el ciudadano de otro Estado, porque es Marruecos la entidad política y no el Rif. En todo caso, no creo que exista entre ellos conciencia nacionalista o afán separatista.

Cara al español, el inmigrante de origen rifeño se define como marroquí; cara al compatriota de origen árabe, como rifeño. La identidad del inmigrante se construye con relación a una serie de factores que se trastocan en buena medida con el cambio migratorio, por cuanto el «otro» (siempre el otro cercano) varía y el esquema individual de referencias se altera. Ciertamente, el origen geográfico y étnico del inmigrante marroquí condiciona ampliamente su círculo de relaciones interpersonales. La pregunta que ahora se plantea es si la fuerza del condicionamiento puede mantenerse en un entorno, el español, donde todos los inmigrantes marroquíes viven en similares condiciones vitales y son contemplados uniformemente desde las instancias oficiales y por parte de la población nacional. P. Pumares apunta el hecho de que la identidad rifeña pudiera acentuarse en el extranjero, "fuera del contexto arabizador de Marruecos» (1996: 36). Ciertamente es en el exilio — sobre todo en Holanda o Alemania, países con considerable volumen de rifeños- donde surgen con más fuerza grupos que reclaman la independencia del Rif y su autonomía cultural y lingüística respecto del resto de Marruecos. puede ocurrir también que incluso que desde las filas árabes la distancia en relación con los rifeños continúe marcándose como estrategia de promoción colectiva consistente en señalar a otros grupos por debajo del propio. No me es posible responder a esta cuestión de forma tajante, pero sí noto en algunos casos que la forma en que el inmigrante se percibe a sí mismo y en relación con los demás varía en alguna medida con la antigüedad de la llegada a España, de manera que es posible observar entre quienes llevan más tiempo instalados entre nosotros un mayor énfasis en su condición de marroquíes o de pobres - nacionalidad o clase- que de rifeños. En contra de la afirmación de Pumares y dentro igual- 
mente del ámbito de las hipótesis, cabría esperar que a la vista de grandes distancias las menores se minimicen, de manea que la separación entre rifeños y árabes iría perdiendo fuerza cuando ambos se enfrentan a la mirada uniformizadora del que es más extranjero, el español: la comunidad de destino, la clase social compartida en el exterior, pueden actuar como factores aglutinantes. Lo cierto es que la afirmación pública de la especificidad rifeña es propia de una élite distanciada del rifeño «medio» y que la suya es, de nuevo, una construcción culta e ideológica.

\subsection{Exageración de la posición social y económica de partida}

Entre los marroquíes de origen rifeño pocos reconocen de partida su origen rural y se adscriben a la ciudad más próxima, Alhucemas. Esta estrategia y la exageración del propio origen social y nivel económico en el país de origen sí son frecuentes - tanto entre árabes como beréberes- como mecanismos conpensatorios, formas de autopresentación que tergiversan la realidad pero que cumplen una función psicológica para el individuo.

¿Qué sugiere la comparación ente las diferentes formas de reconstrucción de la identidad en inmigrantes peruanos y marroquíes? En primer lugar, que en ambos casos la dimensión compensatoria de la reconstrucción es evidente. En segundo lugar, que el inmigrante incorpora indudablemente los parámetros valorativos de la sociedad receptora en su autoconsideración, aunque la reacción no tenga por qué verificarse en un único sentido: puede implicar apertura hacia lo ajeno o repliegue sobre lo propio $^{12}$. El examen detallado de las diferentes estrategias identitarias de ambas poblaciones sugiere un evidente paralelismo en algunos casos, fundamentalmente en cuanto a la exageración de la posición social y económica de origen, cuyo significado es muy similar al de la estrategia de acriollamiento o de ostentación consumista. En términos de E. Goffman (1970), todas estas estrategias pueden catalogarse de formas de encubrimiento de los aspectos que pueden revelar a una persona como desacreditable, haciendo uso de símbolos de prestigio (ostentación consumista, exageración de la posición social de origen) o de desidentificadores (camuflaje, acriollamiento) que oculten la identidad social real tras una identidad social virtual. La dimensión ideológica de la identificación africana acaso tenga bastante en común con la recuperación del orgullo imperial entre los peruanos. La versión vívida de la identificación africana, como expresión de la comunidad de destino con los inmigrantes subsaharianos, se opone a la estrategia de desmarcamiento respecto de los compatriotas observada entre algunos peruanos: el elemento común es la clase social, que en el primer caso une y en el segundo separa. No considero que por ahora tal estrategia de desmarcamiento tenga lugar entre los marroquíes, en primer lugar porque poquísimos entre ellos han tenido ocasión de promocionarse socialmente en España; en segun- 
do lugar, debido al trato que reciben, por lo general, de los españoles, en cuyo imaginario están presentes como lo «último de lo último». La sublimación de la identidad de partida entre los marroquíes tampoco tiene un correlato exacto en las formas de reconstrucción identitaria de los peruanos, precisamente porque el choque cultural es mucho más intenso en el primer caso, de modo que la reacción también es susceptible de serlo. Finalmente, considerar la posibilidad de cierta afinidad entre el «camuflaje» peruano y la «ostentación consumista» de ciertos jóvenes urbanitas marroquíes: es posible que la asunción de la vestimenta moderna por parte de estos jóvenes pudiera interpretarse en cierta medida en términos similares al camuflaje, pero no exactamente, puesto que aquélla acontece sobre todo entre personas — sobre todo cuando hablamos de hombres - que ya habían asumido estos hábitos vestimentarios en Marruecos... la diferencia es que aquí tienen más donde elegir.

Las formas de autopresentación en el nuevo contexto están relacionadas con las cinco variables mencionadas al iniciar este análisis. Estas variables están relacionadas entre sí, de modo que puede considerarse que todas condicionan la primera, a saber, el carácter del entorno inmediato de relaciones personales. Así, el efecto de estas variables sobre las formas de autopresentación está mediado por el auditorio de referencia para el individuo: cabe considerar, idealmente, que el inmigrante ubicado en lugares geográficos con pocos compatriotas, con considerable estatus social de partida, proyecto migratorio individual y definitivo... tenderá a incorporar como auditorio de referencia la sociedad española, incorporando en su escenificación los valores de ésta y recurriendo así a formas de autopresentación en las que a menudo se hace uso de estrategias de encubrimiento o a la recuperación del orgullo indígena. En el extremo opuesto, idealmente, podríamos considerar la situación de que quien emigró en solitario para mantener a su familia considera temporal su proyecto migratorio y nutre aquí su entorno inmediato de compatriotas, y a veces está ubicado en zonas de alta concentración de inmigrantes: en este caso el auditorio de referencia para el individuo no es la sociedad española, de modo que es poco probable que recurra al encubrimiento en su presentación cotidiana, aunque sí puede exagerar su posición social de origen o sublimar sus referentes identitarios originales, estrategias ambas susceptibles de reportar compensación en el entorno considerado. Como vemos, en encubrimiento no solo es opción factible si el auditorio es español, también lo es si se nutre de compatriotas: uno y otro definen determinados rasgos como desacreditables y condicionan, así, las formas concretas de autopresentación. Todas las descritas pueden interpretarse como representaciones que incorporan los valores estereotipados del nuevo contexto - auditorio español—, pero algunas de ellas son válidas para ambos auditorios —español e inmigrante_- como es el caso de la exageración de la posición social de origen, el acriollamiento o la sublimación de la identidad de origen.

En conclusión, si el contacto con la sociedad receptora implica el enfrentamiento de valores y comportamientos diferentes a los aprehendidos en la sociedad de origen, la respuesta de los inmigrantes ante el cambio puede osci- 
lar, idealmente, entre la opción por la afirmación absoluta de lo propio o el olvido absoluto de los mismo y la adhesión completa a los valores del nuevo contexto. En medio, la mayoría de las opciones reales, distintas formas de presentación social que, sin embargo, no creo que puedan considerarse definitivas por cuanto la autoconsideración del inmigrante zizaguea con el carácter y la intensidad de su relación con el nuevo entorno social. De hecho, no es extraño que el individuo atraviese diferentes "ciclos de afiliación» ${ }^{13}$. Así, en ocasiones los procesos de desmarcamiento se ven sucedidos por formas de presentación en las que opera una recuperación radical de lo propio (orgullo indígena, sublimación de la identidad de origen...). De este modo, si el encubrimiento es «una de las fases de la socialización de la persona estigmatizada y un momento decisivo en su carrera moral [...], el individuo estigmatizado puede llegar a sentir que debería estar por encima del encubrimiento, que si se acepta y se respeta a sí mismo no sentirá necesidad de ocultar su defecto» (E. Goffman, 1970: 122). En todo caso, considero, no debe desdeñarse la dimensión social del proceso, por cuanto la oscilación puede ser precipitada también por la respuesta del auditorio español ante los intentos de aproximación del individuo, por el fracaso de los mismos.

\section{Bibliografía}

AA.VV. (1988). «Situación en España de los inmigrantes procedentes de países de mayoría islámica». La Acción Social, Cuadernos de Formación, 5. Madrid: Cáritas.

Altamiro, T. (1992). Exodo. Peruanos en el exterior. Lima: Fondo editorial de la Pontificia Universidad Católica del Peú.

Aparicio, R.; TORnOS, A. (coords.) (1997). Los peruanos que vienen: quiénes son y cómo entienden típicamente la inmigración, los inmigrantes peruanos. Madrid: Universidad Pontificia de Comillas.

Aranguren, J.L. (1993). "El Yo, el sí mismo, el otro y el Otro». Revista de Occidente, 140. Madrid: CAM.

BurkitT, I. (1991). Social Selves: Theories of the social Formation Personality. Londres: Sage.

ChaKer, S. (1991). «Berbères: question nationale?, question culturelle? Le cas de l'Algérie (Kabylie)». L'événement européen. París: Seuil.

Goffman, E. (1970). Estigma, la identidad deteriorada. Buenos Aires: Amorrortu.

- (1987). La presentación de la persona en la vida cotidiana. Madrid: AmorrortuMurguía.

Kepel, G. (1992). Les banlieues de l'Islam. Naissance d'une religion en France. París: Le Seuil.

Lamo de Espinosa, E. (ed.) (1995). Culturas, Estados, ciudadanos. Una aproximación al multiculturalismo en Europa. Madrid: Alianza.

13. «Dada la ambivalencia que crea en el individuo la pertenencia a su categoría estigmatizada, es lógico que aparezcan oscilaciones en el apoyo, en las identificaciones y en la participación que tienen entre sus pares» (E. Goffman, 1970: 52). 
LANDOWSKI, E. (1993). «Ellos y nosotros: notas para una aproximación semiótica a algunas figuras de la alteridad social». Revista de Occidente, 140. Madrid: CAM. PÁEZ, M.T. (1993). «Cultura marroquí y migración». En GimÉnEZ, C. (coord.). Inmigrantes extranjeros en Madrid, tomo II. Madrid: CAM.

PumARES, P. (1996). La integración de los inmigrantes marroquies. Familias marroquies en la Comunidad de Madrid. Barcelona: Fundació La Caixa.

Ramírez Goicoechea, E. (1996). Inmigrantes en España: vidas y experiencias. Colección «Monografías», núm. 147. Madrid: CIS.

SAN ROMÁN, T. (comp.) (1986). Entre la marginación y el racismo. Reflexiones sobre la vida de los gitanos. Madrid: Alianza.

Simmel, G. (1977). «Disgresión sobre el extranjero». Revista de Occidente, vol. II. Madrid: Fundación Ortega y Gasset.

Tornos, A. (1994). «La familia, secreto de la integración». Simposio Vivir en familia, un derecho del trabajador inmigrante, organizado por ASTI en colaboración con la Universidad Pontificia de Comillas. Madrid, 3-5 de junio de 1994. 